\title{
Sense of coherence, career adaptability and burnout of early-career Black staff in the call centre environment
}

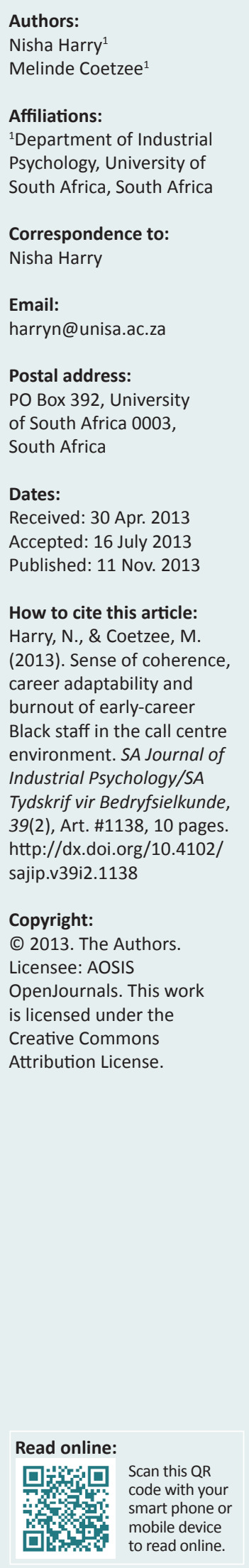

Orientation: The call centre is recognised as being a stressful work environment that affects the general wellbeing of call centre agents.

Research purpose: This study explored whether call centre agents' sense of coherence significantly influences their career adaptability and whether their burnout levels significantly moderate the sense of coherence-career adaptability relationship. The research also investigated whether age, gender and years of service (as control variables), along with sense of coherence, predicted career adaptability.

Motivation for the study: The positive psychological construct of career adaptability and its association with call centre agents' sense of coherence, burnout, age, gender and years of service have not yet been investigated in the call centre environment.

Research design, approach and method: A cross-sectional quantitative survey design was used. The Orientation to Life, Career Adapt-Abilities Scale and Maslach Burnout Inventory General Scale were administered to a non-probability purposive sample of 409 early-career Black staff employed in three of the largest outsourced financial call centres in Africa.

Main findings: Multiple regression analyses revealed that age, gender and meaningfulness significantly predicted call centre agents' career adaptability, but that their burnout levels do not significantly moderate the sense of coherence-career adaptability relationship.

Practical/managerial implications: Enhancing call centre agents' sense of meaningfulness will increase their levels of career adaptability and career wellbeing.

Contribution/value-add: This research is the first to investigate the construct of career adaptability in the call centre environment and adds new knowledge and insights to the existing wellness and positive psychology literature.

\section{Introduction}

The call centre environment is recognised as being one of the world's most stressful work environments (Harry \& Coetzee, 2011; Jacobs \& Roodt, 2011). Absenteeism, high turnover rates, constant monitoring and surveillance and the emotional labour required for the occupation are some of the key challenges that call centre agents and managers face on a daily basis (Banks \& Roodt, 2011; Borgogni, Consiglio, Allesandri \& Schaufeli, 2012; Consiglio, Borgogni, Allesandri \& Schaufeli, 2013; Poddar \& Madupalli, 2012). These challenges may be compounded by the shifting nature of careers and working in the 21st century world of work. Careers and workplaces have become more chaotic and uncertain in the increasingly-turbulent, highly-competitive and dynamically-changing business environment. Consequently, individuals are required to use their positive psychosocial capital in order to stay employable and to adapt to uncertainty and more frequent career transitions (Avey, Reichard, Luthans \& Mhatre, 2011; Savickas, 2011; Savickas \& Porfeli, 2012).

\section{Background}

Various changes have been noted in the 21st century world of work. The contemporary workplace witnesses a decrease in stability and security in careers (Ferreira, 2012). Workers are expected to take greater control over their own career development (Lent, 2013). The world of work has become fast paced, more diverse and less predictable for an increasing number of workers (Lent, 2013). The emergence of protean and boundaryless careers implies an erosion of a career with a single employer and involves frequent career changes (Lent, 2013) that, in turn, require greater levels of career adaptability (Savickas, 2011). Career adaptability is an adaptive resource enabling individuals to cope with career traumas and transitions in stressful and uncertain times (Ferreira, 2012). As a resiliency resource, career adaptability relates to positive behaviour and the individual's capacity to adapt with greater ease to stress and uncertainty in 
the work environment. Individuals with high levels of career adaptability are generally both cognitively and emotionally more ready to cope with the more predicable tasks of preparing for, and participating in, the work role and with the unpredictable adjustments prompted by changes in work and working roles (Savickas \& Porfeli, 2012).

Changing employment structures and job tenure suggest that call centres may represent a typical example of the 21st century career (Choi, Cheong, \& Feinberg, 2012; Consiglio et al., 2013). Call centres are worthy of investigation because they are seen as being a prime example of a stressful work environment that influences the career wellbeing of individuals. They are typically characterised by low pay, low status, high levels of monitoring and little discussion or opportunity for progression (Consiglio et al., 2013). There are limited career opportunities in a call centre and call centre agents are likely to view their own careers in terms of the acquisition of skills transferable to other sectors, or apparently fragmented employment experiences which are characteristic of protean and boundaryless careers (Choi et al., 2012). A call centre career is generally characterised by shortterm contracts (few years of service), call centre vulnerability to shifting markets and client demands that erode the possibility of career-long employment (Choi et al., 2012).

In terms of person characteristics, the call centre environment is typically a source of employment for a younger workforce or individuals in the early stages of their careers and, hence, only a few years of service (Latif, 2010). In the African employment equity and affirmative action context, earlycareer-stage Black employees appear to dominate the workforce in the call centre environment (Harry, 2011). In addition, the call centre job seems to do little to stimulate creativity and flexibility in the call centre agent, which may increase levels of stress and boredom. Call centre jobs are often equated to factory jobs or assembly lines based on the Tayloristic principles of job design; lacking skill variety and often perceived as being repetitive in nature (Borgogni et al., 2012; Choi et al., 2012; Perry, Rubino \& Witt, 2011). These characteristics of the call centre job may have a negative influence on the agent's career wellbeing and satisfaction and may increase their levels of burnout (Harry, 2011).

Similar to career adaptability, sense of coherence is viewed as a personal resource that acts as a form of resilience to stress and a buffer against burnout experienced in the call centre environment (Harry \& Coetzee, 2011). In the context of the present study, sense of coherence and burnout are viewed as being wellness-related dispositional attributes. Research provides evidence that sense of coherence has a positive effect on call centre agents' psychological wellbeing whereas burnout has a negative influence on their wellbeing, especially in an emotionally-demanding work environment (Bezuidenhout \& Cilliers, 2010). However, there appears to be a paucity of research on how individuals' sense of coherence and burnout relate to their career adaptability. From the research literature, it is further unclear whether the negative aspects associated with individuals' levels of burnout have an adverse influence on the relationship between their sense of coherence and career adaptability (as positive resources of their career wellbeing). It was anticipated that should burnout have a significant moderating effect, wellness interventions in the call centre environment could be suggested so as to alleviate the adverse effects of burnout. This would then optimise call centre agents' sense of coherence and career adaptability and, therefore, their resiliency in the call centre environment. There also seem to be a paucity of research on how the person characteristics of age, gender and years of service relate to individuals' career adaptability in the call centre environment.

\section{Research purpose}

This study focuses on three constructs that are prominent in the contemporary positive psychology literature, namely sense of coherence (Antonovsky, 1991; Louw, Mayer, \& Baxter, 2012; Mayer, 2013), burnout (Boudrias, Morin, \& Brodeur, 2012; De Lange, Dikkers \& Demerouti, 2010) and career adaptability (Savickas, 2010; Savickas \& Porfeli, 2012). Positive psychology emphasises developing and maintaining wellbeing and personal strengths (Wong, 2011). Whilst sense of coherence and career adaptability are regarded as being important psychosocial career meta-capacities that have a positive influence on individuals' general career wellbeing and resiliency (Coetzee, 2013; Mayer, 2013; Savickas \& Porfeli, 2012; Van Vianen, Klehe, Koen \& Dries, 2012), burnout is seen to negatively influence their wellbeing, especially in the call centre environment (Harry, 2011). The constructs of sense of coherence and burnout have been researched extensively in the call centre environment (Harry, 2011). However, the notion of career adaptability has not yet been researched in this environment. Moreover, research within the call centre environment was conducted mainly on ways of preventing and treating undesired states of health (Borgogni et al., 2012; Consiglio et al., 2013; Perry et al., 2011). According to Akanji (2012), the field of coping is broadening its scope toward positive striving emotions and searching for meaning in one's life and career. Borgogni et al. (2012) posit that external as well as internal resources are particularly likely to be found in interactionally-intense settings such as customer service work. The repetitive and sustained nature of these service interactions not only increases stress levels of the agents but also heightens an awareness amongst workers of the need for obtaining external as well as internal resources in order to cope and thrive in stressful and demanding situations.

This research focuses on the positive aspects and strengths of human behaviour and psychological functioning (Diener et al., 2010) and the interaction effect of burnout on the relationship between positive psychological strengths. By investigating the relationship between sense of coherence, burnout and career adaptability in the call centre environment, the present research further endeavours to contribute to the wellness and positive psychology literature. More specifically, the research is interested in answering the following research question:

- Does the call centre agents' level of burnout moderate significantly the relationship between their sense of coherence and career adaptability? 
In the context of the present study, age, gender and years of service were treated as control variables. In the light of research showing that the typical call centre agent in the African context is a Black individual in his or her early career stage (with only a few years of service) (Harry, 2011), the research is also interested in investigating whether these person characteristics, along with individuals' sense of coherence, significantly predict their career adaptability in the call centre environment. Age, gender and years of service appear to have a significant influence on individuals' levels of sense of coherence, career adaptability and burnout. Individuals who are older tend to have a higher sense of coherence, with men having stronger sense of coherence than women (Bezuidenhout \& Cilliers, 2010). Years of service relate to call centre agents' ability to maintain a career within a call centre work environment. Research has shown that individuals in the early stages of their careers (and with fewer years of service) tend to have higher levels of adaptability, with women showing higher adaptability than men (Ferreira, 2012). In relation to burnout, younger workers appear to be more prone to experience burnout than older employees (Bezuidenhout \& Cilliers, 2010). However, it is not clear how call centre agents' age, gender and years of service (as control variables) relate to their career adaptability. The research therefore also endeavours to answer the following research question:

- Do call centre agents' age, gender, years of service in the call centre and their sense of coherence positively and significantly predict their career adaptability?

\section{Review of the literature}

Sense of coherence: Sense of coherence explains how people feel, how they perceive, behave and cope with demanding and challenging (stressful) situations, as well as how they keep healthy (Louw et al., 2012). As a global life orientation, sense of coherence expresses the extent to which one has a pervasive, enduring and dynamic feeling of coherence, that is, that one's world is ordered, structured and consistent (comprehensible); that situations in life are endurable, manageable or a new challenge; that one's life is meaningful and makes sense on an emotional and not just a cognitive level; and that life's demands are worthy of commitment (Rothmann, Jackson \& Kruger, 2003; Sairenchi et al. 2011).

Sense of coherence can be understood to represent an autonomous personal resource capable of contributing directly to subjective wellbeing (Sairenchi et al., 2011). It also implies stress-coping abilities in relation to stress recognition. Research conducted by Harry and Coetzee (2011) suggests that call centre agents generally tend to have a high sense of coherence which could be attributed to their applying personal resources to enhance their resilience with regard to coping with stressors in the call centre environment.

Research suggests that older people tend to have a stronger sense of coherence than their younger counterparts as a result of the development of the individual's total personality over time. During adolescence, a person's sense of identity develops and, during the twenties. individuals normally develop psychological stability (Bezuidenhout \& Cilliers, 2010). Sairenchi et al. (2011) found that gender accounts for significant differences in sense of coherence. Men tend to have slightly higher levels of sense of coherence than women (Bezuidenhout \& Cilliers, 2010). However, there seems to be a paucity of research regarding sense of coherence in relation to years of service in the call centre environment.

Career adaptability: Donald Super introduced the term 'career adaptability' to conceptualise how adults adjust to the challenges of a changing world of work (Rottinghaus, Buelow, Matyja \& Schneider, 2012; Super \& Kidd, 1979). Career adaptability relates to the professional duties, traumas, events, situations and transitions that individuals find themselves having to deal with, as well as the psychosocial strategies needed to cope (Savickas \& Porfeli, 2012). Adaptability is the predisposition or propensity to consciously and continually maintain an integration of person and environment and constitutes attitudes, competencies and behaviours that individuals use to fit themselves into professions that suit them (Ferreira, 2012). Adapting proactively to a changing career circumstance reflects the ability to handle constructively the stress of a new or challenging career context (Hirschi, 2012). Career adaptability denotes characteristic self-regulatory psychosocial coping resources which reflect the problemsolving and coping strategies used by people to incorporate the self-concept into their work roles, namely: being concerned about and positively orientated toward the future and linking the past and the present; considering the future as at least controllable and remaining persistent in one's efforts; the willingness to explore the environment by having a sense of curiosity with regard to acquiring information about oneself and the outside world; and having confidence in one's own ability to face the challenges and overcome obstacles and barriers that may be experienced in the pursuit of one's goals (Savickas \& Porfeli, 2012).

There appears to be a paucity of research on the career adaptability of call centre agents. According to Savickas and Porfeli (2012), adaptability is the coping responses or behaviours necessary for an individual to handle the career change tasks with which individuals may be faced. Broadly speaking, adaptability reflects the ability to adjust to change, especially in unpredictable and stressful situations. As a context for career development, the high-stress nature of a call centre environment may have a negative influence on a call-centre agent's career development and job or career satisfaction. High stress and burnout levels have been found to lower career wellbeing in the call centre environment (Choi et al., 2012).

Career adaptability reflects a process through which people build their professional lives in a dynamic manner and at the same time demonstrate the ability to handle changes both proactively and effectively with regard to the particular sociocultural and socioeconomic context within which they live (Coetzee, 2008; Ferreira, 2012). Call centre agents generally experience low levels of career satisfaction due to 
the repetitive and monotonous nature of their work and the limited opportunities for career progression (Choi et al., 2012). Career adaptability appears to be an important construct to consider in terms of coping behaviour because it relates to a call centre agent's resiliency and career satisfaction. The presence of coping resources reduces distress and preserves people's psychological and social equilibrium (Coetzee \& Esterhuizen, 2010). Rossier, Zecca, Stauffer, Maggiori and Dauwalder (2012) posit that as an important set of personal resources, career adaptability exerts a strong impact on career- or work-related outcomes, such as success in the workplace, work engagement, job satisfaction, or job tenure. Research by Lent (2013) revealed that individuals with high levels of career adaptability generally take a proactive stance toward managing their personal life and promoting their own wellbeing.

Research suggests that young, early-career employees are more likely to demonstrate higher levels of adaptability than those in older age categories. Motivation to change decreases with age and proposes that middle-aged individuals should be more adaptable than the elderly (Rostami, Abedi, Bagnhan \& Savickas, 2012). Middle-aged and older adults mazy have negative attitudes toward the developmental experiences that are required in order to become adaptable because such experiences may be taking place at an unexpected time in their lives (Rostami et al., 2012). Gender also relates to individuals' career adaptability, with women showing higher levels of career adaptability than their male counterparts (Ferreira, 2012). However, there seems to be a paucity of research regarding career adaptability in relation to years of service in the call centre environment.

Based on the sense of coherence and career adaptability research literature and role of age and gender in influencing individuals' level of sense of coherence and career adaptability, the following research hypothesis is formulated:

- Hypothesis 1: Individuals' age, gender, years of service in the call centre and sense of coherence positively and significantly predict their career adaptability.

In general, the researchers of the present study expected that sense of coherence as a resiliency resource will strengthen the self-regulatory psychosocial strengths and resiliency capacities embedded in individuals' career adaptability. The research literature suggests that both sense of coherence and career adaptability are associated with individuals' resiliency resources (Cilliers, 2011; Savickas \& Porfeli, 2012). Warner (2011) sees resilience as the ability to adapt to and be successful under difficult or challenging circumstances. Resilient individuals have the potential not only to return to previous levels of functioning after experiencing adversity but to manifest gains in self-esteem, self-efficacy, autonomy and a change in life perspective that serve to make them stronger than they were before (Savickas \& Porfeli, 2012; Warner, 2011). Such gains in adaptive behaviour (termed as thriving or flourishing resilience) are the capacity for recovery and maintained adaptive behaviour that may follow initial threat or incapacity upon initiating a stressful event or manifest competence, despite exposure to significant stressors (Warner, 2011). A strong positive relationship between call centre agents' sense of coherence and their career adaptability was thus expected.

Research further provides evidence of the positive relationship between individuals' age and gender and their sense of coherence (Harry, 2011) and career adaptability (Ferreira, 2012). Early career workers tend to have less years of service in the call centre environment and may retain their high levels of career adaptability as suggested by Rostami et al. (2012).

Burnout: Burnout is seen as persistent, negative, work-related state of mind in 'normal' individuals that is characterised primarily by exhaustion and accompanied by distress; a sense of reduced professional effectiveness; increased feelings of incompetence; decreased motivation and productivity; and the development of dysfunctional attitudes and behaviours (cynicism) at work (Bezuidenhout \& Cilliers, 2010; Boudrias et al., 2012; Brand-Labuschagne, Mostert, Rothmann Jnr \& Rothmann, 2012).

Individuals who experience prolonged and continual exposure to stressors and lack adequate coping strategies may succumb to a state of physical, emotional and mental exhaustion, known as burnout (De Lange et al., 2010; Jordan, Blumenshine, Bertolone \& Heinrich, 2010; Lee \& Choi, 2010). However, individuals who experience stress and who engage in positive coping behaviour are less inclined to burnout (De Lange et al., 2010; Jordan et al., 2010; Lee \& Choi, 2010). Direct and palliative coping styles may play an important role in burnout. A direct coping style is described as problemsolving behaviour through rational and task-orientated strategies, whereas a palliative coping style is described as dealing with emotional distress through strategies such as ignoring the situation. A direct coping style has been associated with lower levels of burnout, whilst a palliative coping style has been associated with higher levels of burnout (De Lange et al., 2010; Jordan et al., 2010; Lee \& Choi, 2010). Research by Harry (2011) indicates that call centre agents tend to experience high levels of burnout and low levels of work engagement. However, having a strong sense of coherence increases the agent's engagement. Low burnout rates are also associated with social coping strategies such as talking with others and finding social support (Choi \& Jin, 2010).

Research shows that men and women experience burnout in fairly similar ways. Slight differences exist in that women tend to experience more of the emotional aspect of burnout (Choi et al., 2012). Younger workers seem to be more prone to experiencing burnout than older workers because with increased age, people generally become more stable and mature (Bezuidenhout \& Cilliers, 2010). However, there seems to a paucity of research regarding burnout in relation to years of service in the call centre environment.

Based on the sense of coherence, career adaptability and burnout research literature, the following null hypothesis is formulated: 
- Hypothesis 2: High levels of sense of coherence and career adaptability will not be influenced negatively by high levels of burnout.

The researchers of the present study expected that sense of coherence and career adaptability will display a direct negative relationship with burnout. They also expect that a strong positive sense of coherence and career adaptability relationship will not be affected by high levels of burnout because of the resiliency resources (positive strengths) that sense of coherence and career adaptability represent. Conservation of Resources theory posits that humans have a basic drive toward the maintenance, conservation and accumulation of resources (Hobfoll, 1989) and these resources act as buffers against and reduce the adverse consequences of stress responses (Bakker \& Demerouti, 2007; Tuckey \& Hayward, 2011).

\section{Research objective and rationale of the study}

Based on the background to the study and the literature review, the research aimed to assess: (1) whether call centre agents' age, gender, years of service in the call centre (as control variables) and their sense of coherence positively and significantly predict their career adaptability; and (2) whether call centre agents' level of burnout significantly strengthens or weakens the relationship between their sense of coherence and career adaptability.

There is a paucity of research on how call centre agents' age, gender, years of service, sense of coherence and burnout levels relate to their career adaptbility. Due to the scarcity of research on the career adaptabiliy construct, it is not clear whether individuals' burnout levels will significantly moderate the sense of coherence-career adaptability relationship, hence the importance of the present research.

\section{The potential value-add of the study}

This research is the first to investigate the construct of career adaptability in relation to sense of coherence, burnout and person characteristics such as age, gender and years of service (as control variables) in the call centre environment and can be regarded as breaking new ground in the wellness and positive psychology literature. The research results may potentially contribute to the body of knowledge on the positive psychological constructs that influence turnover, absenteeism and career wellbeing in the call centre work environment.

The following sections describe the research design, the findings, conclusions and implications for practice and future research.

\section{Research design Research approach}

A quantitative research approach was followed to achieve the research objective. A cross-sectional field survey was conducted that generated primary research data.

\section{Research method}

\section{Participants}

The participants comprised a non-probability purposive sample of 409 early-career Black call centre agents employed in three of the largest outsourced financial call centres in Africa: Johannesburg and Durban (South Africa: $n=364$ ) and Lagos (Nigeria: $n=45$ ). The sample was represented by $65.8 \%$ women and $34.2 \%$ men. The participants were predominantly in the 25-40 year age group (early career; $97 \%$ ). The majority of the participants had between one and two years of service in the call centre environment (67\%) and $33 \%$ had three to 10 years of service.

\section{Measuring instruments}

The Orientation to Life Questionnaire (OLQ-29), developed by Antonovsky (1987), was used to measure the participants' sense of coherence. The OLQ-29 consists of 29 Likert-type self-rating items and respondents are required to make a choice from a seven-point semantic differential scale with two anchoring phrases (Antonovsky, 1987). The OLQ contains three subdimensions, namely: (1) comprehensibility (11 items); (2) manageability (10 items); and (3) meaningfulness (8 items). A South African-based study by Bezuidenhout and Cilliers (2010) reports an overall Cronbach's alpha of 0.90 for the OLQ. In terms of the present study, the following Cronbach alpha (internal consistency reliability) values were obtained (see Table 1): comprehensibility (0.64), manageability (0.57), meaningfulness (0.71) and overall scale (0.78). The present study adopted the social sciences standard of 0.70 as being an acceptable level of internal consistency reliability (Nunnally \& Bernstein, 1994). Only the overall sense of coherence and meaningfulness scales were therefore used for further statistical analyses.

The original, research-based version of the Career AdaptAbilities Scale (CAAS) developed by Savickas (2010) was used to measure the participants' career adaptability. The CAAS is a multi-factorial self-rating measure consisting of 55 items and five subscales: concern (11 items), control (11 items), curiosity (11 items), cooperation (11 items) and confidence (11 items). A five-point Likert-type scale was used for subject responses to each of the 55 items. A South African-based study by Ferreira (2012) reports internal consistency reliability values ranging between 0.88 and 0.90 for the CAAS. The following Cronbach's alpha coefficient (internal consistency reliability) values were obtained for the sample of this study (see Table 1): concern (0.84), control $(0.81)$, curiosity $(0.87)$, cooperation $(0.83)$, confidence $(0.87)$ and overall scale (0.95).

The 16-item Maslach Burnout Inventory General Scale (MBIGS) developed by Maslach, Jackson, and Leiter (1996) was used to assess the participants' level of burnout. The MBI-GS comprises three subscales: exhaustion (5 items), cynicism (5 items) and reduced sense of professional efficacy (6 items). All items were scored on a seven-point Likert-type frequency rating scale, ranging from 0 (never) to 6 (everyday). South African-based studies (Rothmann \& Malan, 2003) report 
internal consistency reliabilities ranging between 0.70 and 0.89. In terms of the present study, the following Cronbach alpha (internal consistency reliability) values were obtained (see Table 1): exhaustion (0.87), cynicism (0.71), professional efficacy (0.73) and overall scale (0.81).

\section{Research procedure and ethical considerations}

Ethical clearance and permission for the research were obtained from the Human Resource manager of the call centres involved, as well as the research institution. Questionnaires were distributed to a non-probability purposive sample of 500 call centre agents. Each questionnaire included a covering letter inviting respondents to participate voluntarily in the study and assuring them that their individual responses would remain anonymous and confidential. The cover letter also stated that completing the questionnaires and returning them constituted agreement to use the results for research purposes only. The research procedure yielded 409 useable questionnaires (response rate $=82 \%$ ).

\section{Statistical analysis}

Preliminary analyses included examination of the internal consistency reliability of the scales and the calculation of zero-order correlation coefficients amongst the scale variables. The main statistical analysis involved: (1) a stepwise multiple-regression analysis to produce a predictive model from the control variables age, gender, years at the call centre and the predictor variable meaningfulness (OLQ) in terms of the five CAAS criterion variables (concern, control, curiosity, cooperation and confidence); and (2) a hierarchical moderated-regression analysis with three steps of entry: in step 1, the effects of the person's characteristics were controlled using the following as covariates: age, gender and years at the call centre. In step 2, the two independent variables (sense of coherence and burnout) were introduced in order to assess the main effects in terms of the career adaptability construct. In step 3, the two-way interaction terms comprising sense of coherence $x$ burnout were entered.

The measurement scores for sense of coherence and burnout were centered prior to the computation of the interaction term. The hierarchical regression model was analysed using the moderated-regression approach recommended by Cohen, Cohen, West and Aiken (2003). Prior to conducting the various regression analyses, collinearity diagnostics were examined to ensure that zero-order correlations were below the level of concern $(r \geq 0.80)$, that the variance inflation factors did not exceed 10, that the condition index was well below 15 and that the tolerance values were close to 1.0 (Field, 2009). In order to counter the probability of a type I error, the significance value was set at the $95 \%$ confidence interval level ( $p \leq 0.05$ ). Cohen's (1992) effect sizes were calculated in order to establish the practical significance of the $R^{2}$ and $\Delta R^{2}$ values.

\section{Results \\ Descriptive statistics}

Table 1 presents the means, standard deviations, internal consistency reliability coefficients and zero-order correlations between the OLQ, MBI and CAAS variables. Due to the low Cronbach's alpha coefficients obtained for the OLQ comprehensibility and manageability subscales $(\alpha<0.70)$, these scales were omitted from the statistical analyses. The participants obtained relatively high scores on the OLQ meaningfulness subscale $(\mathrm{M}=4.91 ; \mathrm{SD}=1.10)$, the $\mathrm{MBI}$ professional efficacy subscale $(\mathrm{M}=4.86 ; \mathrm{SD}=1.04)$, and the CAAS control subscale $(\mathrm{M}=4.26$; $\mathrm{SD}=0.52)$. The participants scored the lowest on the MBI cynicism $(\mathrm{M}=2.64$; $\mathrm{SD}=1.42)$ and CAAS cooperation $(\mathrm{M}=3.78 ; \mathrm{SD}=0.68)$ subscales.

Table 1 further shows that the OLQ meaningfulness variable was not related significantly to the CAAS curiosity variable. Meaningfulness was related both positively and significantly to the other four CAAS variables, namely concern, control, cooperation and confidence $(r \geq 0.11 \leq 0.20 ; p \leq 0.05$; small practical effect). The overall sense of coherence construct was related both positively and significantly to the overall career adaptability construct $(r=0.30 ; p \leq 0.001$; medium practical effect). In terms of burnout (MBI), Table 1 shows that the overall burnout construct related negatively and significantly to the overall sense of coherence construct $(r=-0.22 ; p \leq$ 0.001; small practical effect) and did not relate significantly

TABLE 1: Means, standard deviations, internal consistency reliability coefficients and zero-order correlations $(N=409)$.

\begin{tabular}{|c|c|c|c|c|c|c|c|c|c|c|c|c|c|c|c|}
\hline Variables & $M$ & SD & $\alpha$ & 1 & 2 & 3 & 4 & 5 & 6 & 7 & 8 & 9 & 10 & 11 & 12 \\
\hline Total OLQ & 4.68 & 0.75 & 0.78 & - & - & - & - & - & - & - & - & - & - & - & - \\
\hline Meaningfulness (OLQ) & 4.91 & 1.10 & 0.71 & $0.78 * * *$ & - & - & - & - & - & - & - & - & - & - & - \\
\hline Total MBI & 3.77 & 1.08 & 0.81 & $-0.22 * * *$ & $\mathrm{n} / \mathrm{s}$ & - & - & - & - & - & - & - & - & - & - \\
\hline Exhaustion (MBI) & 2.93 & 1.74 & 0.87 & $-0.35 * * *$ & $-0.38 * * *$ & $0.88^{* * *}$ & - & - & - & - & - & - & - & - & - \\
\hline Cynicism (MBI) & 2.64 & 1.42 & 0.71 & $-0.34 * * *$ & $-0.39 * * *$ & $0.80 * * *$ & $0.68^{* * *}$ & - & - & - & - & - & - & - & - \\
\hline Professional efficacy (MBI) & 4.86 & 1.04 & 0.73 & $0.36 * * *$ & $0.30 * * *$ & $0.38 * * *$ & $\mathrm{n} / \mathrm{s}$ & $\mathrm{n} / \mathrm{s}$ & - & - & - & - & - & - & - \\
\hline Total CAAS & 4.08 & 0.50 & 0.95 & $0.30 * * *$ & $0.45^{* * *}$ & $n / s$ & $-0.14^{* *}$ & $\mathrm{n} / \mathrm{s}$ & $0.19 * * *$ & - & - & - & - & - & - \\
\hline Concern (CAAS) & 4.19 & 0.57 & 0.84 & $0.29 * * *$ & $0.20 * * *$ & $\mathrm{n} / \mathrm{s}$ & $-0.10 *$ & $\mathrm{n} / \mathrm{s}$ & $0.16^{* *}$ & $0.81 * * *$ & - & - & - & - & - \\
\hline Control (CAAS) & 4.26 & 0.52 & 0.81 & $0.27 * * *$ & $0.17^{* * *}$ & $-0.13 * *$ & $-0.20 * * *$ & $-0.15^{* *}$ & $0.14^{* *}$ & $0.84 * * *$ & $0.62 * * *$ & - & - & - & - \\
\hline Curiosity (CAAS) & 4.01 & 0.65 & 0.87 & $0.15^{* * *}$ & $\mathrm{n} / \mathrm{s}$ & $n / s$ & $\mathrm{n} / \mathrm{s}$ & $\mathrm{n} / \mathrm{s}$ & $0.15^{* *}$ & $0.87 * * *$ & $0.61^{* * *}$ & $0.68^{* * *}$ & - & - & - \\
\hline Cooperation (CAAS) & 3.78 & 0.68 & 0.83 & $0.17^{* * *}$ & $0.11 *$ & $n / s$ & $\mathrm{n} / \mathrm{s}$ & $\mathrm{n} / \mathrm{s}$ & $0.10^{*}$ & $0.82 * * *$ & $0.58^{* * *}$ & $0.58^{* * *}$ & $0.63^{* * *}$ & - & - \\
\hline Confidence (CAAS) & 4.16 & 0.60 & 0.87 & $0.24 * * *$ & $0.18^{* * *}$ & $\mathrm{n} / \mathrm{s}$ & $-0.20 * * *$ & $-0.13^{* *}$ & $0.27^{* * *}$ & $0.85^{* * *}$ & $0.60 * * *$ & $0.68 * * *$ & $0.69 * * *$ & $0.62 * * *$ & - \\
\hline
\end{tabular}

OLQ, Orientation to Life Questionnaire ( 1 = minimum; 7 = maximum), MBI, Maslach Burnout Inventory ( 0 = minimum; $6=$ maximum); M, mean; SD, standard deviation; $\alpha$, Cronbach's alpha coefficient; CAAS, Career Adapt-Abilities Scale ( $1=$ minimum; 5 = maximum $)$; $/ \mathrm{s}$, non-significant.

Correlation values $\leq 0.29$ are practically significant (small effect); correlation values $\geq .30 \leq .49$ are practically significant (medium effect); correlation values $\geq 0.50$ are practically significant (large effect). $*, p \leq 0.05 ;{ }^{* *}, p \leq 0.01 ;{ }^{* * *}, p \leq 0.001$. 
to the overall career adaptability construct. Exhaustion was associated both negatively and significantly with concern $(r$ $=-0.10 ; p \leq 0.05 ;$ small practical effect $), \operatorname{control}(r=-0.20 ; p$ $\leq 0.001$; small practical effect) and confidence $(r=-0.20 ; p \leq$ 0.001 ; small practical effect), whilst cynicism was associated both negatively and significantly with control $(r=-0.15 ; p \leq$ 0.01 ; small practical effect) and confidence $(r=-0.13 ; p \leq 0.01$; small practical effect). Professional efficacy was associated both positively and significantly with all the CAAS variables $(r \geq 0.10 \leq .27 ; p \leq 0.05$; small practical effect). It was anticipated that multicollinearity would not pose a problem as the Pearson product-moment coefficients (see Table 1) showed a small to medium practical effect, well below the level of concern for multicollinearity $(r \geq 0.80)$ to be present (Field, 2009).

\section{Stepwise multiple regression analysis}

As reflected in Table 2, the stepwise multiple-regression analysis produced four significant predictive models from the predictor variables age, gender, years at the call centre and meaningfulness (OLQ) in terms of four of the five CAAS variables (concern, control, cooperation and confidence). Overall, in all four regression models $\left(R^{2} \geq 0.04 \leq 0.05\right.$; small practical effect; F $p \leq 0.01$ ), gender and meaningfulness significantly and positively predicted the participants' level of concern, control, cooperation and confidence. Age also positively and significantly predicted the participants' level of control. Meaningfulness contributed the most with regard to explaining the variance in concern $(\beta=0.19 ; p=0.00)$, control $(\beta=0.15 ; p=0.01)$ and confidence $(\beta=0.17 ; p=0.01)$, whilst gender contributed the most toward explaining the variance in cooperation $(\beta=0.16 ; p=0.01)$. The variance inflation factor (VIF) $(>1.0<1.5)$, tolerance $(\leq 1.0)$ and condition index values $(>3<12)$ provided evidence that multicollinearity could be ruled out in all four regression models.

With the exception of years of service, the results provided supportive evidence for the hypothesis $\left(\mathrm{H}_{1}\right)$ that individuals' age, gender, years of service in the call centre and sense of coherence predict their career adaptability both positively and significantly.

\section{Hierarchical moderated regression}

In terms of the overall sense of coherence, burnout and career adaptability constructs, Table 3 shows that the regression model was significant $\left(R^{2}=0.08\right.$; small practical effect; $\mathrm{F} p \leq$ $0.001)$, with gender $(\beta=0.14 ; p=0.01)$ and sense of coherence $(\beta=0.25 ; p=0.00)$ contributing significantly and positively toward explaining the variance in the career adaptability construct. However, the third step of the regression analysis, which examined two-way interactions, was not significant. The $R^{2}$ change was also not significant. The VIF $(>1.0<$ $1.1)$, tolerance $(\leq 1.0)$ and condition index values $(>3<4)$ provided evidence that multicollinearity could be ruled out in the regression model.

As shown in Figure 1, a simple slope test for the regression model confirmed that burnout did not moderate significantly the relationship between the participants' sense of coherence and their level of career adaptability. Figure 1 shows that the sense of coherence-career adaptability relationship was not necessarily stronger for those participants with either high or low levels of burnout.

TABLE 2: Results of stepwise multiple-regression of age, gender, years at call centre and meaningfulness (OLQ) on concern, control, cooperation and confidence (CAAS) $(N=409)$.

\begin{tabular}{|c|c|c|c|c|c|c|c|c|}
\hline Model & Predictor variables & b & SE & $\beta$ & $t$ & $p$ & $\Delta R^{2}$ & Adjusted $R^{2}$ \\
\hline \multirow[t]{5}{*}{1 (concern) } & (constant) & 3.60 & 0.13 & - & 27.41 & $0.001 * * *$ & - & - \\
\hline & Age & -0.04 & 0.06 & -0.03 & -0.60 & 0.71 & - & - \\
\hline & Gender & 0.18 & 0.06 & 0.15 & 3.0 & $0.01 * *$ & - & - \\
\hline & Years at the centre & 0.02 & 0.06 & 0.02 & 0.40 & 0.69 & - & - \\
\hline & Meaningfulness & 0.10 & 0.03 & 0.19 & 3.94 & $0.001^{* * *}$ & $\begin{array}{l}0.04 * * * \\
\Delta \mathrm{F}: 15.52\end{array}$ & $\begin{array}{l}0.05^{* * *} \\
\mathrm{~F}: 6.81\end{array}$ \\
\hline \multirow[t]{4}{*}{2 (control) } & (constant) & 3.76 & 0.12 & - & 31.04 & $0.001 * * *$ & - & - \\
\hline & Gender & 0.15 & 0.05 & 0.14 & 2.79 & $0.01 * *$ & - & - \\
\hline & Years at the centre & -0.001 & 0.06 & -0.001 & -0.01 & 0.99 & - & - \\
\hline & Meaningfulness & 0.07 & 0.02 & 0.15 & 3.09 & $0.01 * *$ & $\begin{array}{l}0.02 * * \\
\Delta \mathrm{F}: 15.52\end{array}$ & $\begin{array}{l}0.05^{* * *} \\
\mathrm{~F}: 6.07\end{array}$ \\
\hline \multirow[t]{4}{*}{4 (cooperation) } & (constant) & 3.31 & 0.16 & - & 20.69 & $0.001 * * *$ & - & - \\
\hline & Age & 0.06 & 0.07 & 0.04 & 0.84 & 0.40 & - & - \\
\hline & Gender & 0.23 & 0.07 & 0.16 & 3.21 & $0.01 * *$ & - & - \\
\hline & Meaningfulness & 0.06 & 0.03 & 0.10 & 1.96 & $0.05 *$ & $\begin{array}{l}0.01 * \\
\Delta \mathrm{F}: 3.86\end{array}$ & $\begin{array}{l}0.03 * * \\
F: 4.08\end{array}$ \\
\hline \multirow[t]{5}{*}{5 (confidence) } & (constant) & 3.65 & 0.14 & - & 26.20 & $0.001 * * *$ & - & - \\
\hline & Age & -0.01 & 0.06 & -0.01 & -0.21 & 0.83 & - & - \\
\hline & Gender & 0.14 & 0.06 & 0.11 & 2.27 & $0.05^{*}$ & - & - \\
\hline & Years at the centre & -0.05 & 0.07 & -0.04 & -0.75 & 0.45 & - & - \\
\hline & Meaningfulness & 0.09 & 0.03 & 0.17 & 3.40 & $0.001 * * *$ & $\begin{array}{l}0.03^{* *} \\
\Delta \mathrm{F}: 11.54\end{array}$ & $\begin{array}{l}0.04 * * \\
F: 4.80\end{array}$ \\
\hline
\end{tabular}

$\mathrm{b}$, unstandardised regression coefficient; $\mathrm{SE}$, standard error; $\beta$, standardised regression coefficient; $t$, obtained $t$-value; $p$, probability; $R^{2}$, proportion variance explained, $\leq 0.12$ (small practical effect size). Model 3 (curiosity) was non-significant and the results are therefore not reported in the table.

Gender: males coded as 0 ; females coded as 1 ; Age: $>25<40$ coded as $0 ;>41$ coded as 1 . All statistics are from the final (second) step.

*, $p \leq 0.05 ;{ }^{* *}, p \leq 0.01 ; * * *, p \leq 0.001$. 
TABLE 3: Results of the moderated-regression analysis examining the interaction effects of sense of coherence (OLQ) and burnout (MBI) in predicting career adaptability (CAAS) $(N=409)$.

\begin{tabular}{|c|c|c|c|c|c|c|c|c|}
\hline Model variables & b & SE & $\boldsymbol{\beta}$ & $t$ & $p$ & $\Delta R^{2}$ & Adjusted $R^{2}$ & $f^{2}$ \\
\hline \multicolumn{9}{|l|}{ Predictor variables } \\
\hline (constant) & 3.97 & 0.05 & - & 78.58 & $0.00 * * *$ & - & - & - \\
\hline \multicolumn{9}{|l|}{ Covariates } \\
\hline Age & 0.02 & 0.05 & 0.02 & 0.39 & 0.70 & - & - & - \\
\hline Gender & 0.14 & 0.05 & 0.14 & 2.77 & $0.01 * *$ & - & - & - \\
\hline Years at centre & -0.003 & 0.06 & -0.003 & -0.05 & 0.96 & - & - & - \\
\hline \multicolumn{9}{|l|}{ Main effects } \\
\hline Sense of coherence & 0.17 & 0.03 & 0.25 & 4.91 & $0.00 * * *$ & - & - & - \\
\hline Burnout & -0.001 & 0.02 & -0.003 & -0.05 & 0.96 & - & - & - \\
\hline \multicolumn{9}{|l|}{ 2-way interaction } \\
\hline Sense of coherence $x$ Burnout & -0.01 & 0.03 & -0.01 & -0.24 & 0.81 & - & - & - \\
\hline Model & - & - & - & - & - & $\begin{array}{l}0.00 \\
\Delta \mathrm{F}: .06\end{array}$ & $\begin{array}{l}0.08^{* * *} \\
\mathrm{~F}: 6.36\end{array}$ & -0.06 \\
\hline
\end{tabular}

$\mathrm{b}$, unstandardised regression coefficient; $\mathrm{SE}$, standard error; $\beta$, standardised regression coefficient; $t$, obtained $t$-value; $p$, probability; $R^{2}$, proportion variance explained, $\leq 0.12$ (small practical effect size); $f^{2}$, effect size estimate for the interaction term.

Beta values of predictor variables are mean-centered. Gender: males coded as 0 ; females coded as 1.

Statistics are from the final (fourth) step.

**, $p \leq 0.01 ;{ }^{* * *}, p \leq 0.001$.

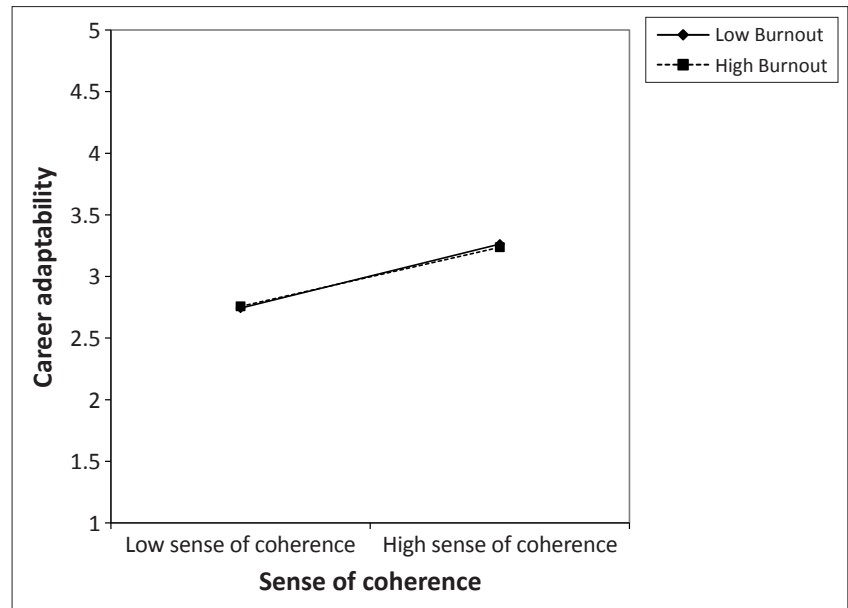

Independent and moderating variables were mean-centered for the moderated regression analysis.

FIGURE 1: Interaction effect between sense of coherence (independent variable) and burnout (moderating variable) on career adaptability $(N=409)$.

The results provided supportive evidence for the research hypothesis $\left(\mathrm{H}_{02}\right)$, which stated that high levels of sense of coherence and career adaptability will not be influenced negatively by high levels of burnout.

\section{Discussion}

The research hypotheses dealt with the predictive influence of individuals' age, gender, years of service in a call centre (as control variables) and their sense of coherence on their level of career adaptability. The research also investigated whether burnout levels significantly moderated the relationship between individuals' sense of coherence and their career adaptability.

In terms of the control variables (age, gender and years of service), the results suggest that gender needs to be considered in order to gain an understanding of the predictive value of meaningfulness and overall sense of coherence in strengthening the participants' career adaptability. Ferreira (2012) found women to have higher levels of career adaptability than their male counterparts. Contrary to research conducted by Ferreira (2012), age also contributed positively toward explaining the participants' sense of control. The association between age and sense of control (selfdiscipline in conscientious and responsible decision making) may be because of the early career being the period during which the life structure of early-career adults becomes more stable as they begin to settle down and become committed to contributing toward an occupation, a company or a person (Coetzee \& Schreuder, 2008). Rostami et al. (2012) also suggest that early-career workers tend to have high levels of career adaptability. Career adaptable individuals are also likely to have strong feelings of attachment toward their organisation and are more likely to engage in self-development activities that will enable them to take advantage of opportunities in their job or career (Ferreira, 2012).

The issue of central theoretical interest in the present study was the relationship between call centre agents' sense of coherence and their career adaptability and the moderating effect of burnout. Sense of coherence and career adaptability are considered to be important positive human strengths or resiliency resources in buffering the negative effects of adverse and traumatic events and situations relating to the work/career environment context (Hirschi, 2012; Louw et al., 2012; Mayer, 2013; Savickas \& Porfeli, 2012). As expected, the results provided evidence that sense of coherence as a resiliency resource strengthens the selfregulatory psychosocial strengths and resiliency capacities embedded in an individual's career adaptability. The sample of participants also had positive perceptions regarding their sense of coherence, sense of meaningfulness and their career adaptability (control).

Career adaptability resources reside at the intersection of person-in-environment and enable individuals to adjust to the challenges of their working lives (Savickas \& Porfeli, 2012). It appears from the results that helping call centre agents to see how their job fits into their personal and work lives and that it is worthy of investment, commitment and engagement is important with regard to enhancing their career adaptability. As a coping (or resiliency resource), sense of coherence 
is assumed to mitigate life stress by affecting the overall quality of individuals' cognitive and emotional appraisal of the stimuli that impact on them (Rothmann et al., 2003). The results showed that a sense of meaningfulness (feeling that life makes sense on an emotional and cognitive level) contributed significantly toward explaining the participants' career adaptability strengths in terms of their concern (orientation to and involvement in preparing proactively for the future), control (self-discipline in conscientious and responsible decision making), cooperation (contributing to and cooperating with the team or community) and confidence in their ability to solve problems and overcome career-related barriers or obstacles (Savickas, 2010; Van Vianen et al., 2012). Rothmann et al. (2003) found that high levels of sense of coherence contribute to the professional efficacy of individuals. Naudé and Rothmann (2006) also found positive links between a strong sense of sense of coherence and engagement.

As expected, negative associations were observed between burnout (exhaustion and cynicism) and sense of coherence and meaningfulness. High levels of concern, control and confidence also seemed to have lowered the participants' levels of exhaustion, whilst high levels of control and confidence have lowered their cynicism. Overall, high levels of professional efficacy appeared to have increased the participants' career adaptability resources. The participants also indicated low burnout levels and high levels of professional efficacy, meaningfulness and career adaptability which may have contributed to the positive associations between these resiliency resources. Moreover, their overall burnout levels did not affect the relationship between their sense of coherence and career adaptability resources. Stress resilience is linked to resources and the investment in resources (Tuckey \& Hayward, 2011). The findings of the present study seem to corroborate the notion that accumulated positive psychosocial resources may alter the perceptions evoked by stressors and even reduce the adverse consequences of stress states and responses (Bakker \& Demerouti, 2007). Research also shows that a strong sense of coherence decreases emotional exhaustion and depersonalisation (Bezuidenhout \& Cilliers, 2010; Harry, 2011; Sairenchi et al., 2011). The lack of association between overall career adaptability and overall burnout may also have contributed to the lack of interaction effects between these variables.

\section{Limitations of the study}

The conclusions about the findings of our study need to be considered in light of a number of limitations, each suggestive of promising directions in the area of research on enhancing call centre agents' career wellbeing and satisfaction. Firstly, the study was cross-sectional in nature and thus the causal direction of relations between the variables cannot be ascertained. Secondly, the study was limited to the call centre environment and to a predominant sample of early-career Black and female participants. The findings can therefore not be generalised to other occupational, age, race and gender contexts. Replication studies, using independent samples drawn from other occupational contexts, are recommended.

\section{Future research}

Given the practical and theoretical importance of positive psychosocial or resiliency resources in contemporary career development, especially within the call centre environment, future research in this area is undoubtedly warranted. Future research initiatives may consider the mediating effect of sense of coherence in the burnout-career adaptability relationship. Longitudinal studies are needed in order to understand how call centre agents' life orientation (sense of coherence) evolves over time and how this influences their career adaptability. Such studies also need to consider variables relating to individuals' evolving career self-concept, their career needs and interests and how these influence their level of sense of coherence, stress resilience and adaptability. Gender was also indicated as being a significant predictor of career adaptability. Future research should explore the differences between men and women in terms of career adaptability.

\section{Conclusions}

Overall, the results of the study added valuable new insights regarding how age, gender, sense of coherence and sense of meaningfulness influence the career adaptability of call centre agents. Attending to the complex process of coping with the challenges and demands of career development in the 21st century work world, especially in the call centre environment, can help individuals to identify personal strengths and other positive psychosocial resources necessary for adjusting to changing contextual circumstances affecting their working lives. Enhancing call centre agents' sense of meaningfulness by helping them to understand why the work is meaningful and where they fit in the broader picture will significantly increase their levels of career adaptability, which in turn may result in more positive work attitudes and career wellbeing in the call centre environment. Insight into the role of sense of coherence and career adaptability in helping individuals to manage their career wellbeing and development through the lifespan have become important in the 21st century work world. This research serves as a stepping stone toward continued research on the positive psychological constructs that may help to structure healthy and flourishing career behaviour in the call centre environment. Considering that this research is the first to investigate the construct of career adaptability in the call centre environment, the study can be regarded as novel and as adding new insights and knowledge to the existing wellness and positive psychology literature.

\section{Acknowledgements Competing interests}

The authors declare that they have no financial or personal relationship(s) which may have inappropriately influenced them in writing this article.

\section{Authors' contributions}

N.H. (University of South Africa) was responsible for the literature review, data collection, manuscript preparation and submission of the manuscript. M.C. (University of South 
Africa) attended to the statistical analyses, interpretation of the results and review of the final manuscript.

\section{References}

Akanji, B. (2012). Realities of work life balance in Nigeria: perceptions of role conflict and coping beliefs. Business, Management \& Education, 10(2), 248-263. http:// dx.doi.org/10.3846/bme.2012.18

Antonovsky, A. (1987). Unraveling the mystery of health: How people manage stress and stay well. San Francisco, CA: Jossey-Bass.

Antonovsky, A. (1991). Personality and stress: individual differences in the stress process. Chichester: Cooper Payne.

Avey, J.B., Reichard, R.J., Luthans, F., \& Mhatre, K.H. (2011). Meta-analysis of the impact of positive psychological capital on employee attitudes, behaviors, and dx.doi.org/10.1002/hrdq.20070

Bakker, A.B., \& Demerouti, E. (2007). The Job Demands-Resources model: state of the art. Journal of Managerial Psychology, 22(3), 309-328. http://dx.doi.org/10.1108/ 02683940710733115

Banks, D., \& Roodt, G. (2011). The efficiency and quality dilemma: What drives South African call centre management performance indicators? SA Journal of Human Resource Management/SA Tydskrif vir Menslikehulpbronbestuur, 9(1), Art. \#331, 17 pages. http://dx.doi.org/10.4102/sajhrm.v9i1.331

Bezuidenhout, A., \& Cilliers, F.V.N. (2010). Burnout, work engagement and sense of coherence in female academics in higher-education institutions in South Africa. SA Journal of Industrial Psychology/SA Tydskrif vir Bedryfsielkunde, 36(1), Art. \#872, 10 pages. http://dx.doi.org/10.4102/sajip.v36i1.872

Borgogni, L., Consiglio, C., Allesandri, G., \& Schaufeli, W.B. (2012). 'Don't throw the baby out with the bathwater': Interpersonal strain at work and burnout. European Journal of Work and Organizational Psychology, 21(6), 875-898. http://dx.doi.org $/ 10.1080 / 1359432 X .2011 .598653$

Boudrias, J., Morin, A.J., \& Brodeur, M.M. (2012). Role of psychological empowerment in the reduction of burnout in Canadian healthcare workers. Nursing \& Health Sciences, 14(1), 8-17. http://dx.doi.org/10.1111/j.1442-2018.2011.00650.x PMid:22288550

Brand-Labuschagne, L., Mostert, K., Rothmann S. Jnr, \& Rothmann, J.C. (2012). Burnout and work engagement of South African blue-collar workers: the development of a new scale. Southern African Business Review, 16(1), 58-93.

Cilliers, F. (2011). Positive psychology leadership coaching experiences in a financial organisation. SA Journal of Industrial Psychology/SA Tydskrif vir Bedryfsielkunde, 37(1), Art. \#933, 14 pages. http://dx.doi.org/10.4102/sajip.v37i1.933

Coetzee, M. (2008). Psychological career resources of working adults: A South African survey. SA Journal of Industrial Psychology/SA Tydskrif vir Bedryfsielkunde, 34(2), 32-41. http://dx.doi.org/10.4102/sajip.v34i2.491

Coetzee, M. (2013). A psychological career resources framework for contemporary career development. In Coetzee M. (ed.), Psychosocial career meta-capacities: Dynamics of contemporary career development (in press). Dordrecht: Springer International.

Coetzee, M., \& Esterhuizen, K. (2010). Psychological career resources and coping resources of the young unemployed African graduate: An exploratory study. SA Journal of Industrial Psychology/SA Tydskrif vir Bedryfsielkunde, 36(1), Art. \#868, 9 pages. http://dx.doi.org/10.4102/sajip.v36i1.868

Coetzee, M. \& Schreuder, A.M.G. (2008). A multi-cultural investigation of students' career anchors at a South African higher education institution. South African Journal of Labour Relations, 32(2), 45-65.

Choi, B.Y., \& Jin, Y.Y. (2010). Work demands and burnout syndrome of military personnel. Nottingham, Nottinghamshire: European Academy of Occupational Health Psychology (EAOHP).

Choi, S., Cheong, K.J., \& Feinberg, R.A. (2012). Moderating effects of supervisor support, monetary rewards, and career paths on the relationship between job burnout and turnover intentions in the context of call centers. Managing Service Quality, 22 (5) 492-516. http://dx.doi.org/10.1108/09604521211281396

Cohen, J. (1992). Quantitative methods in psychology: A power primer. Psychological Bulletin, 112(1), 155-159. http://dx.doi.org/10.1037/0033-2909.112.1.155

Cohen, J., Cohen, P., West, S.G., \& Aiken, L.S. (2003). Applied multiple regression correlation analysis for the behavioral sciences (3rd edn.). Mahwah, NJ: Erlbaum.

Consiglio, C., Borgogni, L., Allesandri, G., \& Schaufeli, W.B., (2013). Does self-efficacy matter for burnout and sickness absenteeism? The mediating role of demands and resources at the indvidual and team levels. Work \& Stress, 27(1), 22-42. http:// dx.doi.org/10.1080/02678373.2013.769325

De Lange, A.H., Dikkers, J.S.E., \& Demerouti, E. (2010). A self-regulatory perspective on the effects of humour styles in relation to burnout and work engagement. Nottingham, Nottinghamshire: European Academy of Occupational Health Psychology (EAOHP).

Diener, E., Wirtz, D., Tov, W., Kim-Prieto, C., Choi, D., Oishi, S., et al. (2010). New wellbeing measures: short scales to assess flourishing and positive and negative feelings. Social Indicators Research, 97(2), 143-156. http://dx.doi.org/10.1007/ s11205-009-9493-y

Ferreira, N. (2012). Constructing a psychological career profile for staff retention. Unpublished doctoral dissertation. University of South Africa, Pretoria, South Africa.

Field, A. (2009). Discovering statistics using SPSS. (3rd edn.). Thousand Oaks: Sage.

Harry, N. (2011). Sense of coherence, affective wellbeing and burnout in a call centre Unpublished Master's thesis. University of South Africa, Pretoria, South Africa.

Harry, N., \& Coetzee, M. (2011). Sense of coherence, affective wellbeing and burnout in a South African higher education insititution call centre. South African Journa of Labour Relations Management, 35(2), 26-46.
Hirschi, A. (2012). The career resources model: an integrative framework for career counsellors. British Journal of Guidance \& Counselling, 40(4), 369-383. http://dx.doi. org/10.1080/03069885.2012.700506

Hobfoll, S.E. (1989). Conservation of resources. A new attempt at conceptualizing stress. American Psychologist, 44(3), 513-524. http://dx.doi.org/10.1037/0003066X.44.3.513, PMid:2648906

Jacobs, C., \& Roodt, G. (2011). A human capital predictive model for agent performance in contact centres. SA Journal of Industrial Psychology/SA Tydskrif vir Bedryfsielkunde, 37(1), Art. \#940, 19 pages. http://dx.doi.org/10.4102/sajip.v37i1.940

Jordan, J., Blumenshine, E., Bertolone, M., \& Heinrich, F. (2010). Burnout among intellectual disability staff. Poster presented at 2010 APA Convention, 12-15 August, San Diego.

Latif, J. (2010). An investigation into the moderating effects of hardiness between performance monitoring and life satisfaction in a call centre environment. Unpublished Master's thesis. University of Witwatersrand, Johannesburg, South Africa.

Lee, S. M., \& Choi, B. Y. (2010). Individual and work-related factors influencing burnout of mental health professionals: a meta-analysis. Presentation at 9th Conference of the European Academy of Occupational Health Psychology, 29-31 March 2010, Rome.

Lent, R.W. (2013). Career-life preparedness: revisiting career planning and adjustment in the new workplace. The Career Development Quarterly, 61(1), 2-14. http:// in the new workplace. The Career Development
dx.doi.org/10.1002/j 2161-0045 2013.00031.x

Louw, L., Mayer, C., \& Baxter, J. (2012). Exploring relationship between value- and lifeorientation and job satisfaction. Acta Commercii, 12(1), 44-66.

Maslach, C., Jackson S.E., \& Leiter, M.P. (1996). Maslach Burnout Inventory Manua (3rd edn.). Mountain View, CA: Mindgarden.

Mayer, C.H. (2013). Sense of coherence and career development. In M. Coetzee (Ed.), Psychosocial career meta-capacities: Dynamics of contemporary career development (in press). Dordrecht: Springer International.

Naudé, J.L.P. \& Rothmann, S. (2006). Work-related well-being of emergency workers in Gauteng. South African Journal of Psychology, 36(1), 63-81. http://dx.doi.org/ 10.1177/008124630603600105

Nunnally, J.C. \& Bernstein, I.H. (1994). Psychometric theory (3rd edn.). New York: McGraw-Hill.

Perry, S.J., Rubino, C., \& Witt, L.A. (2011). General job performance of first-line supervisors: the role of conscientiousness in determining its effects on subordinate exhaustion. Stress \& Health, 27(2), 83-93. http://dx.doi.org/10.1002/smi.1339

Poddar, A., \& Madupalli, R. (2012). Problematic customers and turnover intentions of customer service employees. Journal of Services Marketing, 26(7), 551-559. http://dx.doi.org/10.1108/08876041211266512

Rossier, R., Zecca, G., Stauffer, S.D., Maggiori, C., \& Dauwalder, J.P. (2012). Career adapt-abilities scale in a French-speaking Swiss sample: psychometric propertie and realtionships to personality and work engagement. Journal of Vocationa Behavior. 80(3), 734-743. http://dx.doi.org/10.1016/j.jvb.2012.01.004

Rostami, Z., Abedi, M.R., Bagnhan, I, \& Savickas, M.L. (2012), Toward career salvation's model, a primary study: case study. Interdisciplinary Journal of Contemporary Research, 4(2), 1133-1139.

Rothmann, S., Jackson, L.T.B., \& Kruger, M.M. (2003). Burnout and job stress in a local government: the moderating effect of sense of coherence. SA Journal of Industrial Psychology/SA Tydskrif vir Bedryfsielkunde, 29(4), 52-60. http://dx.doi. org/10.4102/sajip.v29i4.122

Rothmann, S., \& Malan, H. (2003). Koherensiesin, selfdoeltreffendheid, lokus van beheer en uitbranding by maatskaplike werkers [Sense of coherence, self-efficacy, locus of control and burnout of social workers]. SA Journal of Industrial Psychology/SA Tydskrif vir Bedryfsielkunde, 29(4), 43-51. http://dx.doi.org/10.4102/sajip.v29i4.125

Rottinghaus, P.J., Buelow, K.L., Matyja, A., \& Schneider, M.R. (2012). The career futures inventory-revised: measuring dimensions of career adaptability. Journal of Career Assessment, 20(2), 123-139. http://dx.doi.org/10.1177/1069072711420849

Sairenchi, T., Haruyama, Y., Ishikawa, Y., Wada, K., Kimura, K., \& Muto, T. (2011). Sense of coherence as a predictor of onset of depression among Japanese workers: A cohort study. BMC Public Health, 11(1), 205-209. http://dx.doi.org/10.1186/1471-245811-205

Savickas, M. (2010). The career adapt-abilities scale. Personal documentation received from author at the 27th International Congress of Applied Psychology (ICAP) 11-16 July, Melbourne.

Savickas, M.L. (2011). New questions for vocational psychology: premises, paradigms, and practices. Journal of Career Assessment, 19(3), 251-258. http://dx.doi.org/ 10.1177/1069072710395532

Savickas, M.L., \& Porfeli, E.J. (2012). Career adapt-abilities scale: construction, reliability, and measurement equivalence across 13 countries. Journal of Vocational Behavior 80(3), 661-673. http://dx.doi.org/10.1016/j.jvb.2012.01.011

Super, D.E., \& Kidd, J.M. (1979). Vocational maturity in adulthood: toward turning a model into a measure. Journal of Vocational Behavior, 14(3), 255-270. http://dx.doi. org/10.1016/0001-8791(79)90054-X

Tuckey, M.R., \& Hayward, R. (2011). Global and occupation-specific emotional resources as buffers against the emotional demands of fire-fighting. Applied Psychology 60(1), 1-23. http://dx.doi.org/10.1111/j.1464-0597.2010.00424.x

Van Vianen, A.E.M., Klehe, U.C., Koen, J., \& Dries, N. (2012). Career adapt-abilities scale Netherlands form: psychometric properties and relationships to ability, personality and regulatory focus. Journal of Vocational Behavior, 80(3), 716-724. http://dx.doi. org/10.1016/j.jvb.2012.01.002

Warner, R. (2011). What is resilience? Management Today, 29(1), 16-19.

Wong, P.T.P. (2011). Positive psychology 2.0: towards a balanced interactive model of the good life. Canadian Psychology, 52(2), 69-81. http://dx.doi.org/10.1037/a0022511 